\title{
THỰC TRANG KIẾN THỨC Về TIÊM CHỦNG CỦA CÁC BÀ ME CÓ CON DƯớI 1 TUỔI TẠI PHƯỜNG TỨ MINH, HẢI DƯƠ'NG, THÁNG 12 NĂM 2018
}

\begin{abstract}
TÓM TẮT.
Mục tiêu: Mô tả thực trạng kiến thức về tiêm chủng và một số yếu tố ảnh hưởng đến kiến thức về tiêm chủng cho trẻ của các bà mẹ có con dưới 1 tuổi tại phường Tứ Minh tháng 12/2018. Đối tượng và phương pháp nghiên cứu: Nghiên cứu mố tả cắt ngang trên 120 bà me có con dưới một tuổi đang sinh sống tại phường Tứ Minh, thành phố Hải Dương, trong tháng 12/2018. Kết quả: Tỷ lệ các bà mẹ cho rằng tiêm chủng là rất quan trọng và quan trong chiếm $72,5 \%$ và $25,8 \% ; 75,8 \%$ các bà mẹ cho rằng tiêm chủng phòng được nhiều bệnh truyền nhiếm. Đa số hiểu đúng về các bệnh được phòng bởi tiêm chủng chỉ có $0,8 \%$ bà me không biết. Đa số các bà me có kiến thức đúng về lịch tiêm chủng các loại vắc xin có tỷ lêt trên $70 \%$. Chỉ có 3,4\% các bà me không biết về chống chỉ định tiêm chủng và $7,6 \%$ cho rằng không có chống chỉ định; $0,8 \%$ cho rằng không phải hoãn tiêm; $0,8 \%$ cho rằng không có tác dung phụ khi tiêm vắc xin. Hoat động thông tin - giáo dục - truyền thông của địa phương ảnh hưởng đến kiến thức của các bà mẹ về tiêm chủng $(p=0,003)$.
\end{abstract}

SUMMARY

THE CURRENT SITUATION OF KNOWLEDGE ABOUT IMMUNIZATION OF MOTHERS WITH CHILDREN UNDER 1 YEAR OLD IN TU MINH WARD, HAI DUUONG PROVINCE IN DECEMBER 2018

Objective: Describe the current situation of knowledge about immunization and some factors affecting mothers' knowledge about vaccination for children under 1 year old in Tu Minh ward in December 2018. Subjects and methods: Crosssectional descriptive survey on 120 mothers with children under one year old living in Tu Minh ward, Hai Duong city, in December 2018. Results: The rate of mothers supposing that vaccination is very important and important reached $72.5 \%$ and $25.8 \% ; 75.8 \%$ of mothers said that vaccination could prevent many infectious diseases. Most mothers correctly understood about diseases prevented by vaccination, only $0.8 \%$ of mothers did not know. Mothers with correct knowledge of vaccination schedule are over $70 \%$. Only $3.4 \%$ of mothers did not know about contraindications to vaccination and $7.6 \%$ supposed that there were no contraindications; $0.8 \%$ said that the injection should not be delayed; $0.8 \%$

*Trường Đại học Kỹ thuật Y tế Hải Dương Chịu trách nhiệm chính: Nguyễn Thị Nga Email: ngadhyhn@gmail.com Ngày nhận bài: 19.2.2021

Ngày phản biện khoa học: 30.3.2021

Ngày duyệt bài: 12.4.2021

\section{Nguyễn Thị Nga*, Phạm Thị Ngân*}

said there were no side effects on vaccine injections. Local information - education - communication activities affect mothers' knowledge about vaccination $(p=0.003)$.

\section{I. ĐẶT VẤN ĐỀ}

Tiêm chủng là biện pháp hiệu quả trong việc tạo ra miễn dịch sớm giúp trẻ có thể phòng chống được các bệnh truyền nhiễm nguy hiểm đến tính mạng. Hiện nay đã có gân 30 bệnh truyền nhiễm có thể dự phòng được bằng vắc xin [1]. Ở Việt Nam tiêm chủng được triển khai từ năm 1981 với 6 loại vắc xin phòng bệnh lao, bạch hâu, ho gà, uốn ván, sởi, bại liệt. Năm 1997, 04 vắc xin mới được triển khai miễn phí trong chương trình TCMR của Việt Nam là vắc xin viêm gan $B$, vắc xin viêm não Nhật Bản $B$, vắc xin thương hàn, vắc xin tả. Tháng 6/2010, vắc xin Hib phòng các bênh viêm phổi năng và viêm màng não mủ do Hib được triển khai trên toàn quốc, năm 2015 triển khai thêm vắc xin rubella trong tiêm chủng thường xuyên [2]. Tuy nhiên nếu trẻ em không được tiêm chủng hoặc tiêm chủng không đây đủ, tiêm chủng muộn thì nguy cơ dịch bệnh quay trở lại là rất lớn, gây nguy hiểm cho sức khỏe trẻ em và toàn thể cộng đồng. Vì những lý do cấp thiết như trên, tôi tiến hành nghiên cứu đề tài "Thực trạng kiến thức về tiêm chủng của các bà mẹ có con dưới 1 tuổi tại phường Tứ Minh, tháng 12 năm 2018"

Mục tiêu: Mô tả thực trạng kiến thức về tiêm chủng của các bà mẹ có con dưới 1 tuôi tại phương Tứ Minh, tháng 12 năm 2018 và một số yếu tố liên quan.

\section{II. ĐỐI TƯỢNG VÀ PHƯƠNG PHÁP NGHIÊN CỨU}

*Đối tượng nghiên cứu: Những bà mẹ có con $\leq 01$ tuổi (trẻ được sinh từ 01/01/2018 đến 31/12/2018) đang thường trú tại phường Tứ Minh - thành phố Hải Dương - tỉnh Hải Dương trong tháng 12/2018

\section{*Phương pháp nghiên cứu}

Thiết kế nghiên cứu: Nghiên mô tả cắt ngang. Cỡ mấu:

Tính theo công thức $\mathrm{n}=\frac{Z_{1-\alpha / 2}^{2} \cdot P(1-P)}{d^{2}}$

-n: Cõ mẫu nghiên cứu

$-Z^{2} 1-\alpha / 2$ : Hệ số tin cậy $\left(a=95 \% ; Z_{1-\alpha / 2}:=1.96\right)$

- $\mathrm{P}$ : Tỷ lể bà mẹ có con $\leq 01$ tuổi có kiến thức về sự cẩn thiết tiêm chủng $\mathrm{p}=81,3 \%$ theo 
tác giả Huỳnh Giao [3]

- d: Mức sai số ước lượng giữa tham số mẫu và quần thể. Chọn $\mathrm{d}=0,05$

Ap dụng công thức ta có cỡ mẫu nghiên cứu là: 120 người

Chọn mẫu ngẫu nhiên phân tâng: chọn bằng phương pháp ngẫu nhiên trong tất cả 8 khu của phường (Nhật Tân, Tứ Thông, Xuân Dương, Thượng Đạt, Cẩm Khê, Đỗ Xá, Lộ Cương, Tân Minh), mỗi khu 15 bà mẹ có con dưới 1 tuổi.

*Phương pháp thu thập số liệu

- Phỏng vấn trực tiếp tại nhà bà mẹ có con $\leq$ 01 tuổi

- Công cụ thu thập số liệu: Bộ câu hỏi phỏng vấn

*Phương pháp phân tích số liệu. Nhập số liệu bằng chương trình phần mềm Epidata, quản lý và phân tích số liệu bằng phần mềm SPSS 16.0 .

\section{KẾT QUẢ NGHIÊN CỨU}

3.1. Thông tin chung về đối tượng nghiên cứu

Bảng 3.1: Thông tin chung về đôi tượng nghiên cứu

\begin{tabular}{|c|c|c|c|}
\hline Đặc điểm & Nội dung thông tin. & $\begin{array}{c}\mathbf{n} \\
\text { (nqười) }\end{array}$ & $\begin{array}{l}\text { Tỳ } \\
\mid \mathbf{e ̂}(\%)\end{array}$ \\
\hline \multirow{3}{*}{$\begin{array}{l}\text { Nhóm } \\
\text { tuổi }\end{array}$} & $<25$ tuối & 31 & 25,8 \\
\hline & Từ $25-35$ tuối & 79 & 65,8 \\
\hline & $>35$ tuối & 10 & 8,3 \\
\hline \multirow{4}{*}{$\begin{array}{l}\text { Trình đố } \\
\text { học vấn }\end{array}$} & Cấp 1 & 1 & 0,8 \\
\hline & Cấp 2 & 12 & 10 \\
\hline & Cấp 3 & 62 & 51,7 \\
\hline & $\begin{array}{l}\text { Trên PTTH (Trung } \\
\text { cấp, Cao đắng, Đại } \\
\text { hoc, Trên ĐH) }\end{array}$ & 45 & 37,5 \\
\hline \multirow{6}{*}{$\begin{array}{c}\text { Nghề } \\
\text { nghiệp }\end{array}$} & Nội trợ & 14 & 11,7 \\
\hline & Nông dần & 5 & 4,2 \\
\hline & Công nhân & 58 & 48,3 \\
\hline & $\begin{array}{l}\text { Cán bộ, công chức, } \\
\text { viên chức nhà nước }\end{array}$ & 18 & 15 \\
\hline & Buôn bán/ kinh doanh & 21 & 17,5 \\
\hline & \begin{tabular}{c|} 
Khác \\
\end{tabular} & 4 & 3,3 \\
\hline \multirow{2}{*}{$\begin{array}{l}\text { Thu nhâp } \\
\text { bình quân } \\
\text { người/tháng }\end{array}$} & $>=4$ riệu & 87 & 72,5 \\
\hline & < 4 triệu & 33 & 27,5 \\
\hline \multirow{4}{*}{$\begin{array}{l}\text { Số con của } \\
\text { bà mẹ }\end{array}$} & 1 con & 50 & 41,7 \\
\hline & 2 con & 52 & 43,3 \\
\hline & 3 con & 18 & 15 \\
\hline & Nhiều hơn & 0 & 0 \\
\hline
\end{tabular}

Các bà mẹ tham gia nghiên cứu: phần lớn trong độ tuổi 25-35 (65,8\%); trình độ học vấn từ cấp 3 trở lên (cáp 3: $51,7 \%$ và trên cấp 3 là 37,5\%); nghề nghiệp đa dạng, trong đó công nhân chiếm tỷ lệ nhiều nhất là 48,3\%; thu nhập bình quân $\geq 4$ triệu/ 1 tháng chiếm $72,5 \%$; hầu hết các gia đình có 1 hoặc 2 con (lần lượt là $41,7 \%$ và $43,3 \%$ )

\subsection{Kiến thức về tiêm chủng}

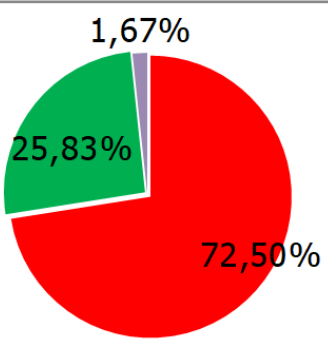

$$
\begin{aligned}
& \text { - Rất quan trọng } \quad \text { Quan trọng } \\
& \text { - Không quan trọng }
\end{aligned}
$$

\section{Biểu đồ 3.1: Tỷ lệ kiến thức về mức độ quan trong của tiêm chủng}

Đa số các bà mẹ được nghiên cứu cho rằng tiêm chủng là rất quan trọng cho trẻ dưới 1 tuổi chiếm $72,5 \%$, chỉ có $1,67 \%$ bà mẹ cho rằng tiêm chủng không quan trọng.

Bảng 3.2: Tỷ lệ đối tượng hiêu biêt về lợi ích tiêm chủng

\begin{tabular}{|c|c|c|}
\hline $\begin{array}{c}\text { Hiểu biết về lợi ích của tiêm } \\
\text { chưng }\end{array}$ & $\begin{array}{c}\text { Tân } \\
\text { số }\end{array}$ & $\begin{array}{c}\text { Tỷ } \\
\text { lệ }\end{array}$ \\
\hline $\begin{array}{c}\text { Phòng bệnh của nhiều bệnh } \\
\text { truyền nhiếm }\end{array}$ & 91 & 75,8 \\
\hline $\begin{array}{c}\text { Sau khi tiêm sẽ không bao giờ } \\
\text { bị mắc bệnh đấy nữa }\end{array}$ & 26 & 21,7 \\
\hline Không biết & 3 & 2,5 \\
\hline
\end{tabular}

Có 75,8\% đối tượng nghiên cứu hiểu biết được lợi ích của tiêm chủng, $21,7 \%$ hiểu sai về lợi ích của tiêm chủng, 2,5\% không biết câu trả lời.

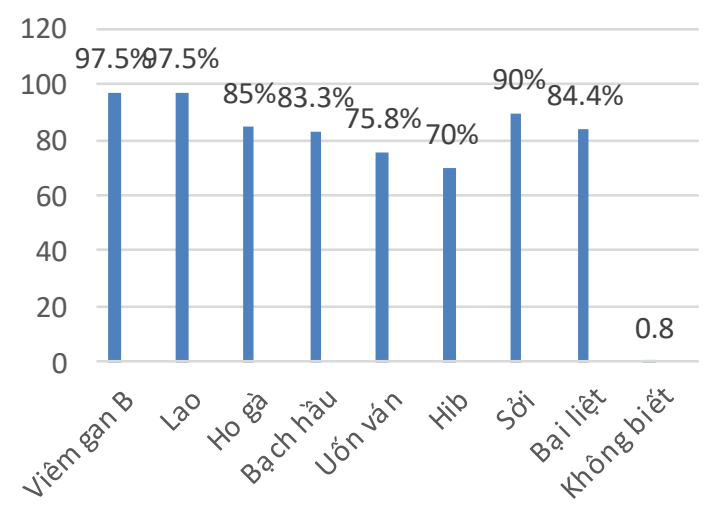

\section{Biêu đồ 3.2: Hiểu biêt của các bà me về các bênh có thể phòng bằng vacxin}

Đa số các bà mẹ hiểu biết về các bệnh có thể phòng nhờ vacxin. Chỉ có $0,8 \%$ đối tượng nghiên cứu không biết câu trả lời. 


\begin{tabular}{|c|c|c|c|}
\hline \multicolumn{2}{|c|}{ Hiểu biết lịch tiêm chủng } & $\begin{array}{c}\text { Tân } \\
\text { số }\end{array}$ & $\begin{array}{l}\text { Tỷ } \\
\text { lệ }\end{array}$ \\
\hline \multirow{2}{*}{$\begin{array}{c}\text { So } \\
\text { sinh }\end{array}$} & $\begin{array}{c}\text { - Tiêm vacxin viêm gan } \\
\text { B (VGB) mũi } 0 \text { trong } \\
24 \text { h đâu sau sinh }\end{array}$ & 86 & 71,7 \\
\hline & $\begin{array}{l}\text { - Tiêm vacxin BCG } \\
\text { phòng bệnh lao }\end{array}$ & 115 & 95,8 \\
\hline \multirow[t]{2}{*}{$\begin{array}{c}02 \\
\text { tháng }\end{array}$} & $\begin{array}{l}\text { - Tiêm vacxin bạch hâu- } \\
\text { ho gà- uốn ván- viêm } \\
\text { gan B- Hib B mũi } \\
1(\text { Vacxin } 5 \text { trong } 1)\end{array}$ & 93 & 77,5 \\
\hline & - Uống vacxin bại liệt & 93 & 77,5 \\
\hline
\end{tabular}

\begin{tabular}{|c|c|c|c|}
\hline & lần 1 & & \\
\hline \multirow{2}{*}{$\begin{array}{c}03 \\
\text { tháng }\end{array}$} & $\begin{array}{c}\text { - Tiêm vacxin5 trong 1 } \\
\text { mũi 2 }\end{array}$ & 102 & 85 \\
\cline { 2 - 4 } & $\begin{array}{c}\text { - Uống vacxin bại liệt } \\
\text { lần 2 }\end{array}$ & 102 & 85 \\
\hline $\begin{array}{c}04 \\
\text { tháng }\end{array}$ & $\begin{array}{c}\text { - Tiêm vacxin5 trong 1 } \\
\text { mũi 3 }\end{array}$ & 90 & 75 \\
\cline { 2 - 4 } & $\begin{array}{c}\text { - Uống vacxin bại liệt } \\
\text { lần 3 }\end{array}$ & 85 & 70,8 \\
\hline $\begin{array}{c}09 \\
\text { tháng }\end{array}$ & - Tiêm vacxin sởi mũi 1 & 91 & 75,8 \\
\hline
\end{tabular}

Phần lớn các bà mẹ tham gia nghiên cứu nhớ được lịch tiêm phòng vacxin cho trẻ dưới 1 tuổi chiếm trên $70 \%$.

Bảng 3.4: Tỷ lệ hiêu biết về chống chỉ định và chỉ định tạm hoãn tiêm chủng

\begin{tabular}{|c|c|c|}
\hline Chống chỉ định tiêm vacxin & Tânsố & Tỉ lệ \\
\hline 1. Trẻ có tiền sử sốc hoặc phản ứng nặng sau tiêm chủng vacxin lần trước & 88 & 73,9 \\
\hline $\begin{array}{l}\text { 2. Trẻ có tình trạng suy chức năng các cơ quan (như suy hô hấp, suy tuần } \\
\text { hoàn, suy tim, suy thận, suy gan, ...). }\end{array}$ & 83 & 69,7 \\
\hline $\begin{array}{l}\text { 3. Trẻ suy giảm miển dịch (HIV/AIDS, bệnh suy giảm miễn dịch bẩm sinh) } \\
\text { chống chỉ định tiêm chủng các loại vacxin sống. }\end{array}$ & 73 & 61,3 \\
\hline 4. Không có chống chỉ định & 9 & 7,6 \\
\hline 5. Không biết & 4 & 3,4 \\
\hline Trường hợp tạm hoãn & Tân số & Tỉ lệ \\
\hline 1. Trẻ mắc các bệnh cấp tính, đặc biệt là các bệnh nhiểm trùng. & 92 & 76,7 \\
\hline 2. Trẻ sốt $\geq 37,5^{\circ} \mathrm{C}$ hoăc hạ thân nhiệt $\leq 35,5^{\circ} \mathrm{C}$ (đo nhiệt độ tại nách). & 102 & 85 \\
\hline $\begin{array}{l}\text { 3. Trẻ mới dùng các sản phẩm globulin miê̂n dịch trong vòng } 3 \text { thángtrừ' } \\
\text { trường hợp trẻ đang sử dụng globulin miễn dịch điều trị viêm gan B. }\end{array}$ & 39 & 32,5 \\
\hline $\begin{array}{l}\text { 4. Trẻ đang hoặc mới kết thúc liêu điêu trị corticoid (uống, tiêm) trong vòng } \\
14 \text { ngày. }\end{array}$ & 45 & 37,5 \\
\hline 5. Trẻ sơ sinh có cân nặng dưới $2000 \mathrm{~g}$. & 73 & 60,8 \\
\hline 6. Không cần hoãn tiêm chủng & 1 & 0,8 \\
\hline
\end{tabular}

Đa số các bà mẹ tham gia nghiên cứu có hiểu biết về chống chỉ định và các trường hợp tạm hoãn của tiêm vacxin; chỉ có $3,4 \%$ không biết về chống chỉ định, $7,6 \%$ cho rằng không có chống chỉ định và $0,8 \%$ cho rằng không cần hoãn tiêm. Tuy nhiên hiểu biết về các trường hợp tạm hoãn sau sử dụng các sản phẩm globulin miễn dịch và điêu trị corticoid còn hạn chế $(32,5 \%)$.

Bảng 3.5: Tỷ lệ hiếu biết về tác dụng phu sau tiêm chủng

\begin{tabular}{|c|c|c|}
\hline $\begin{array}{c}\text { Tác dụng phụ gặp phải sau } \\
\text { tiêm vacxin }\end{array}$ & $\begin{array}{c}\text { Tân } \\
\text { số }\end{array}$ & $\begin{array}{c}\text { Tỷ } \\
\text { lệ }\end{array}$ \\
\hline Không có tác dụng phụ & 1 & 0,8 \\
\hline Sốt & 108 & 90 \\
\hline Sưng đỏ đau tại chố & 106 & 88,3 \\
\hline Nối hạch & 84 & 70 \\
\hline Quấy khóc & 111 & 92,5 \\
\hline Tiêu chảy & 71 & 59,2 \\
\hline Mệt chán ăn buồn nôn & 61 & 50,8 \\
\hline Phát ban & 66 & 55 \\
\hline Tác dụng phụ khác & 10 & 8,3 \\
\hline
\end{tabular}

Phần lớn các bà mẹ tham gia nghiên cứu hiểu biết về tác dụng phụ sau tiêm vacxin, chỉ có $0,8 \%$ bà me trả lời khổng có tác dụng phụ.

Bảng 3.6: Tỷ lệ hiếu biết về các phản ứng phù sau tiếm cần đưa trẻ đến viện

\begin{tabular}{|c|c|c|}
\hline Phản ứng phụ & $\begin{array}{c}\text { Tân } \\
\text { số }\end{array}$ & Tỷ lệ \\
\hline $\begin{array}{c}\text { Sốt từ } 37,5-38,5^{\circ} \mathrm{C} \text {, sưng } \\
\text { đau tại chố }\end{array}$ & 13 & 10,8 \\
\hline Chán ăn, phát ban & 22 & 18,3 \\
\hline Tiêu chảy & 28 & 23,3 \\
\hline $\begin{array}{c}\text { Quấy khóc kéo dài, khóc } \\
\text { thét, bỏ bú }\end{array}$ & 75 & 62,5 \\
\hline Sốt sao >= 39² , co giật & 118 & 98,3 \\
\hline Tím tái, khó thở, thở nhanh & 107 & 89,2 \\
\hline Nối hạch & 31 & 25,8 \\
\hline Không biết & 0 & 0 \\
\hline
\end{tabular}

Phần lớn ĐTNC biết về phản ứng phụ sau tiêm chủng cần đưa trẻ đển viên gồm: quấy khóc kéo dài, khóc thét, bỏ bú; Sốt sao >= $39^{\circ} \mathrm{C}$, co giật; tím tái, khó thở, thở nhanh. 


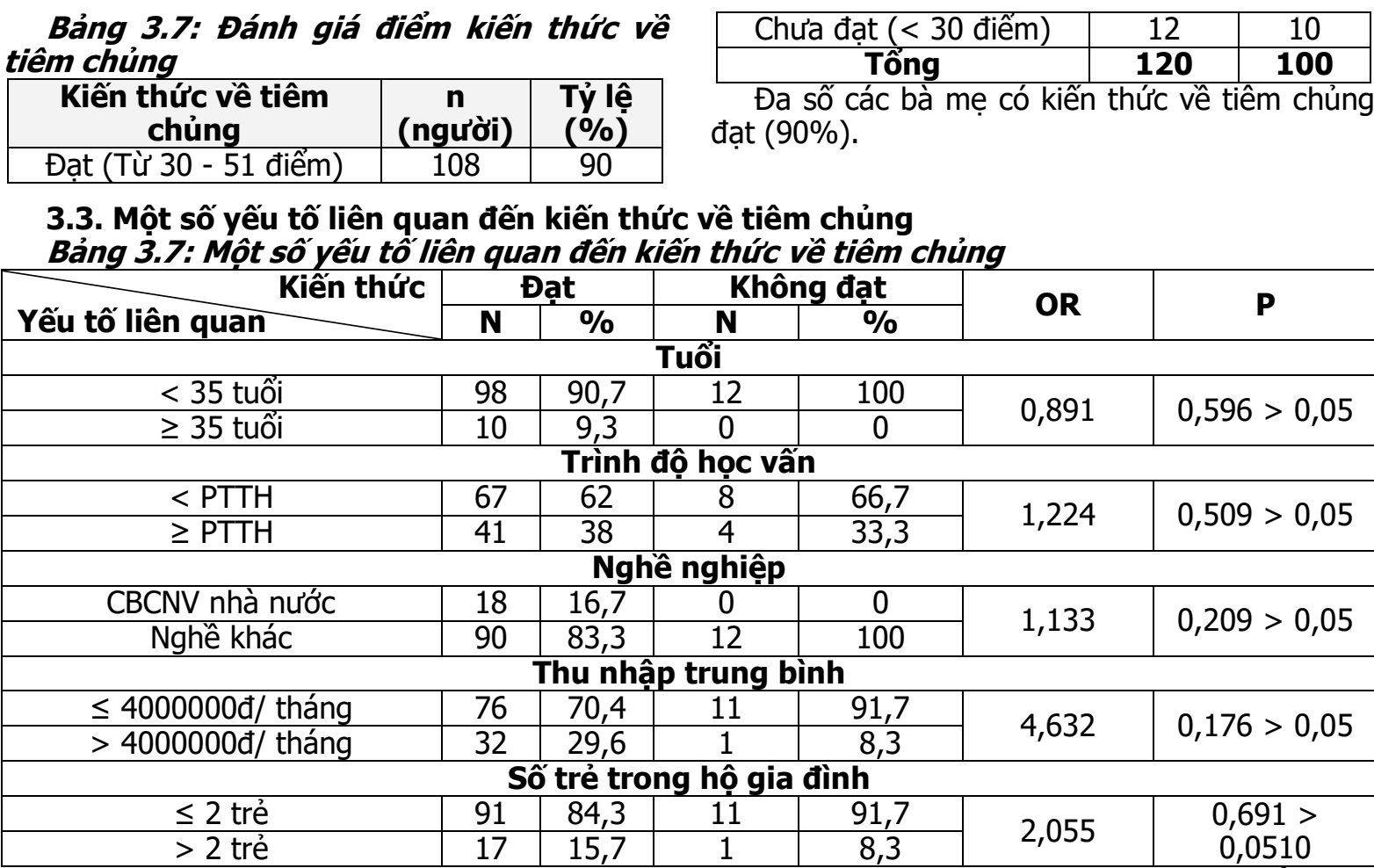

Không có sự khác biệt giữa những người có kiến thức đạt và không đạt về các yễu tố: tuối, trình độ học vấn, nghề nghiệp, thu nhập trung bình, số trẻ trong hộ gia đình.

Bảng 3.8: Môi liên quan giữa hoạt động Thông tin - giáo dục - truyền thông (TT-GDTT) đến kiến thức về tiêm chủng

\begin{tabular}{|c|c|c|c|c|c|c|}
\hline \multirow{2}{*}{ TT-GD -TT Kiến thức } & \multicolumn{2}{|c|}{ Đạt } & \multicolumn{2}{|c|}{ Không đạt } & \multirow{2}{*}{ OR } & \multirow[b]{2}{*}{$\mathbf{p}$} \\
\hline & $\mathbf{N}$ & $\%$ & $\mathbf{N}$ & $\%$ & & \\
\hline Đạt hiệu quả & 83 & 95,4 & 4 & 4,6 & 6.64 & $0.003<0.05$ \\
\hline Chưa hiệu quả & 25 & 75,8 & 8 & 24,2 & 0,04 & כ \\
\hline Tống & 108 & & 12 & & & \\
\hline
\end{tabular}

Hoạt động thông tin - giáo dục - truyền thông hiệu quả làm tăng tỷ lệ bà mẹ có kiến thức đúng về tiêm chủng mở rộng, có ý nghĩa thống kê với $\mathrm{p}<0,05$

\section{BÀN LUÂN}

4.1. Về kiến thức của bà me về tiêm chủng mở rộng. Kết quả nghiên cứu cho thấy $72,5 \%$ các bà mẹ được nghiên cứu cho rằng tiêm chủng là rất quan trọng cho trẻ dưới 1 tuổi, $25,8 \%$ cho rằng tiêm chủng là quan trọng. Kết quả nghiên cứu này cao hơn nghiên cứu của tác giả Dương Anh Dũng và cộng sự tại Lạng Sơn năm 2015 với tỷ lệ các bà mẹ có hiểu biết đúng về kiến thức tiêm chủng chỉ đạt $75,4 \%$.Điều này có thể lý giải là do mỗi địa phương có khả năng tiếp cận với thông tin tiêm chủng khác nhau [3].

Đa số các bà me biết được tác dụng của tiêm chủng $(75,8 \%)$ nhưng vẫn còn các bà me hiểu sai về tác dụng của tiêm chủng $(21,7 \%)$, cho rằng sau khi tiêm sẽ không bao giờ mắc lại bệnh này nữa, dẫn đến tình trạng chủ quan trong việc phòng bệnh cho con và mất niềm tin vào tiêm chủng khi con mắc bệnh đã được tiêm phòng.

Tỷ lệ các bà mẹ trả lời tiêm chủng phòng được 8 bệnh truyền nhiễm nguy hiểm ở trẻ em gồm lao, viêm gan $B$, ho gà, bạch hầu,bại liệt, uốn ván, $\mathrm{Hib}$, sởi lần lượt là $97,5 \% ; 97,5 \%$; $85 \% ; 83,3 \% ; 84,2 \% ; 74,8 \% ; 70 \% ; 90 \%$. Tuy nhiên tỷ lệ này vẫn thấp hơn so với nghiên cứu của Phan Lê Thu Hằng tại huyện Thanh Hà, Hải Dương năm 2014 - 2015: lao, Hib, bại liệt là $100 \%$, sởi là $98 \%$, viêm gan B là $97 \%$, bạch hầu, ho gà, uốn ván là $92,3 \%$.

Tỷ lệ các bà me có kiến thức về lịch tiêm trong nghiên cứu này đạt tỷ lệ từ 70,8 - 95,8\%, thấp hơn của Phan Lê Thu Hằng là 100\% [5], tương đồng với nghiên cứu của Nguyễn Thành Huế, với tỷ lệ tiêm chủng đúng lịch cho từng loại vacxin là: Lao $72,41 \%$; DPT - Hib đạt $85,85 \%$, VGB là 85,69\%; Bại liệt đạt 85,37\%; Sởi mũi 1 là 
$81,91 \%$ [6]. Kiến thức về hoãn tiêm và chống chỉ định trong nghiên cứu của chúng tôi cũng chiếm tỷ lệ cao chỉ có trường hợp trẻ mới dùng globulin miễn dịch trong 3 tháng và trường hợp trẻ đang hoăc mới kết thúc điều trị corticoid trong vòng 14 ngày chỉ có $32,5 \%$ và $37,5 \%$ biết cần hoãn tiêm. Vì đây là kiến thức chuyên môn nên ít bà me biết đến.

Tỷ lệ các bà mẹ có hiểu biết về phản ứng phụ thông thường khi tiêm vắc xin như sốt $(90 \%)$, quấy khóc $(92,5 \%)$, đau sưng nhe chố tiêm $(88,3 \%)$, kiến thức cần biết về biểu hiện đưa trẻ đến CSYT như: sốt cao co giật $(98,3 \%)$, quấy khóc kéo dài, khóc thét, bỏ bú $(62,5 \%)$, khó thở, tím tái, thở nhanh $(89,2 \%)$. Kết quả này cao hơn của Phan Lê Thu Hằng [5].

4.2. Bàn luận về một số yếu tố liên quan đến kiến thức của các bà mẹ về tiêm chủng

Các yếu tố như tuổi tác, trình độ học vân, nghề nghiệp, kinh tế, số con không ảnh hưởng đến kiến thức của bà mẹ về tiêm chủng $(p>0,05)$

Trong các đối tượng được truyền thông hiệu quả có 83 người có kiến thức tốt về tiêm chủng, chiếm 95,4\%, sự khác biệt giữa nhóm kiến thức đạt và không đạt là có ý nghĩa thông kê $(p<0,05)$. Vì vậy cần đẩy mạnh công tác truyền thông tai địa phương cả về mặt nội dung và hình thức để nâng cao kiến thức của các bà mẹ về tiêm chủng.

\section{KẾT LUẬN}

1. Kiến thức của các bà me về tiêm chủng mở rộng. Các bà mẹ cho rằng tiêm chủng là rất quan trọng và quan trọng chiếm $72,5 \%$ và $25,8 \%$.

Có $75,8 \%$ các bà me biết được tác dụng của tiêm chủng nhưng vẫn có $21,7 \%$ hiểu sai.
Đa số hiểu đúng về các bệnh được phòng bởi tiêm chủng chỉ có $0,8 \%$ bà mẹ khồng biết. Chỉ có $3,4 \%$ và $0,8 \%$ các bà mẹ không biết về chống chỉ định tiêm và hoãn tiêm chủng.

Tỷ lệ có kiến thức tiêm chủng đạt là $90 \%$

2. Yếu tố ảnh hưởng đến kiến thức tiêm chủng của các bà mẹ. Yếu tố tuổi, trình độ học vấn, nghề nghiệp, kinh tế, số con không liên quan đến kiến thức tiêm chủng của các bà mẹ $(p>0,05)$

Hoạt động thông tin - giáo dục - truyền thông của địa phương có ảnh hưởng tích cực đến kiến thức của các bà mẹ về tiêm chủng, có ý nghĩa thống kê $(p=0,003)$.

\section{TÀI LIẸU THAM KHẢO}

1. Bộ Y tế (2014), Quyết định về phê duyêt "Kế hoạch truyên thông về việc tiêm chủng giai đoạn 2014-2016, 4282/QĐ-BYT.

2. WHO (2005), Thực hành tiêm chủng, GPXB số 58/QĐ-CXB cấp ngày 9/3/2005, Hà Nội.

3. Huỳnh Giao, Pham Lê An (2010), "Kiến thức thái độ của các bà me có con dưới 1 tuổi về tiêm chủng trong tiêm chủng mở rộng, thuốc chủng phối hợp, thuốc chủng Rotavirus, Human Papiloma Virus tại bệnh viện Nhi Đồng 2 và quận Tân Phú Tp Hồ Chí Minh năm 2009", tạp chí Ý học Tp.Hồ Chí Minh, Tập 14, Phụ bản số 2, trang 27.

4. Dương Anh Dũng (2017), "Thực trạng tiêm chủng, kiến thức, thái độ, thực hành tiềm chủng mở rộng tại 2 huyện biên giới của tỉnh Lạng Sơn năm $2015^{\prime \prime}$, tap chí Ý học dự phòng. Số 1 , trang 77.

5. Phan Lê Thu Hằng (2016), "Kiến thức và thực hành của các bà me có con đủ 12 tháng tuổi về tiêm chủng mở rộng tại huyện Thanh Hà, Hải Dương năm 2014 - 2015", tạp chí $Y$ học dự phòng. Số 5 , trang 158 .

6. Nguyền Thành Huế (2016), "Thực trạng tiêm chủng đầy đủ, đúng lịch 8 loại vacxin ở trẻ em dưới 1 tuổi và một số yếu tố liền quan tại khu vực ngoại thành thành phô Hà Nội năm 2016", Tạp chí Y học dự phòng.Số 3, trang 98.

\section{THIẾT LÂP BẢNG ĐIỂM DỰA VÀO SIÊU ÂM ĐỂ TIÊN ĐOÁN SỐT XUẤT HUYẾT DENGUE Có SỐC Ở TRẺ EM}

\section{TÓM TẮT.}

Đặt vấn đề: Siêu âm là phương tiện đơn giản giúp phát hiện dịch ổ bụng và màng phổi ở bệnh nhân

\footnotetext{
${ }^{1}$ Dai học Y Dược Cần Tho

${ }^{2}$ Bênh viên An Giang

Chịu trách nhiệm chính: Nguyễn Ngọc Rạng

Email: nguyenngocrang@gmail.com

Ngày nhận bài: 24.4.2021

Ngày phản biên khoa học: 31.3.2021

Ngày duyệt bài: 9.4.2021
}

\section{Nguyễn Ngọc Rạng ${ }^{1}$, Dương Kim Thu ${ }^{2}$}

bị Sốt xuyết huyết dengue (SXHD). Mục tiêu: thiết lập bảng điểm dựa vào siêu âm đề tiên đoán SXHD có sốc Đối tượng và phương pháp: Đối tượng gồm 446 bệnh nhi SXHD có siêu âm, từ 1-14 tuổi, được truy cứu từ bệnh án lưu trũ tại bệnh viện An Giang. Dùng mô hình hồi qui logistic đảa biến để xác đinh các biến có khả năng tiên đoán sốc. Kết quả: Có tất cả 446 bệnh nhân (154 có sốc và 292 không sốc) được siêu âm trong giai đoạn tiền sốc. Tỉ lệ có tụ dịch ở 6 vị trí (túi Morison, túi cùng Douglas, dịch dưới bao gan, dịch tự do ổ bụng, dịch màng phối phải và trái) và dày thành túi mật (TTM) ở nhóm sốc cao hơn nhóm không 